\title{
The effect of anisotropy orientation on the sedimentary rock strength estimated by point load testing strength, Pilbara, Australia
}

\author{
X Gao Rio Tinto Iron Ore, Australia
}

\begin{abstract}
Mine slope geotechnical design requires an engineering estimation of the intact rock's uniaxial compressive strength, which is influenced by the anisotropic nature of sedimentary rocks. In order to determine the rock's anisotropic behaviour, numerous rock samples from diamond drilling were tested in the field by using the point load test (PLT) method. The effect of anisotropy on the calculated point load strength $\left(I_{s(50)}\right)$ from axial and diametral point load testing was investigated. The finding of this paper can be used to select $\sigma_{c i}$ input for the Hoek-Brown failure criteria based on low-cost PLT results.
\end{abstract}

Keywords: anisotropy index $\left(I_{a}\right)$, point load test, point load strength $\left(I_{s(50)}\right)$, banded iron formation, shale

\section{Introduction}

Banded iron formation (BIF) and shale are typical sedimentary rocks within the Pilbara region of Western Australia. The term BIF describes a sedimentary geological formation that has alternating bands or layers of iron oxide-rich and chert-rich material (RioTinto 2010).

The main feature of BIF in Pilbara is regular banding in different scales in the order from $1 \mathrm{~mm}$ to several metres. The rock mass strength of BIF is dependent on the inter-bedded macro shale band, structures and the intact BIF strength.

Apart from the weak geological bands in BIF, significantly spatial variability in the degree of rock mass weathering degree also can affect the intact rock strength anisotropy. However, other variables like stratigraphy units were not discussed due to the limited sample quantity in this paper.

Mercer (2012) stated that bedding is the predominant plane of weakness laid down in sedimentary rocks especially for BIF and shale. An anisotropic linear model has been developed for modelling the weak bedding shear strength by Snowden since 2005.

The anisotropy of intact sedimentary rock including BIF and shale is indicated by the anisotropic index $\left(I_{a}\right)$ in terms of the function of the results obtained with the application of the load in a parallel and perpendicular manner to the anisotropy planes with vary bedding angles. The anisotropic index can be used to select the uniaxial compressive strength (UCS) relative to the angle of anisotropy, which is an important input for the derivation of rock mass strength criterion including the Hoek-Brown failure criteria. The anisotropic index can be estimated by rock mechanical tests such as point load test (PLT), UCS and triaxial tests.

This paper is a preliminary step of researching the anisotropic behaviour of intact BIF and shale core samples, by changing the orientation of micro iron oxide bands in the directions of parallel (diametral) and perpendicular (axial) to the loading direction.

A series of axial and diametral PLT tests have been carried out to characterise the anisotropic behaviour of intact BIF and shale rock. The advantages of the PLT are portability, low cost and low requirement level of samples sizes, which makes PLT samples' distribution is much larger than other laboratory compression tests. This work presents the effect of anisotropy orientation on BIF core samples' anisotropic index $\left(I_{a}\right)$ and 
concluded the diameral PLT results cannot be used to estimate the intact BIF UCS as it is significantly lower than axial PLT results.

\section{Geology background}

The Hamersley Group is a $2.5 \mathrm{~km}$ thick sequence of late Archaean to Paleoproterozoic marine sedimentary and volcanic rock that overlies approximately $40,000 \mathrm{~km}^{2}$ of the southern Pilbara Craton, Western Australia. The BIF-derived ore hosted by the Hamersley Group comprises the largest tonnage of known iron ore resources in the Hamersley province (RioTinto 2010).

The main feature of BIF in the province is its regular banding. The banding is due to numerous rhythmic variations in composition. The Hamersley Group (Figure 1) contains five major BIF units, of which two, the Marra Mamba Iron Formation and the Brockman Iron Formation host most of the high-grade iron ore deposits developed to date. BIF is regarded by mining businesses as a waste rock (in some cases ore can be recovered subject to beneficiation) because of high gangue content in proportion to iron oxides. BIF is often the major component of the final pit wall after the rich mineralisation is mined out and its strength can affect the stability of mined slopes. BIF intact strength is one component of the overall rock mass strength.

The BIF samples selected and tested in the experimental section are from the Joffre member (JOF) which is part of the Brockman formation and the shale samples are from JOF, Whaleback shale (WS), Mount McRae shale, and Wittenoom Formation (WF).

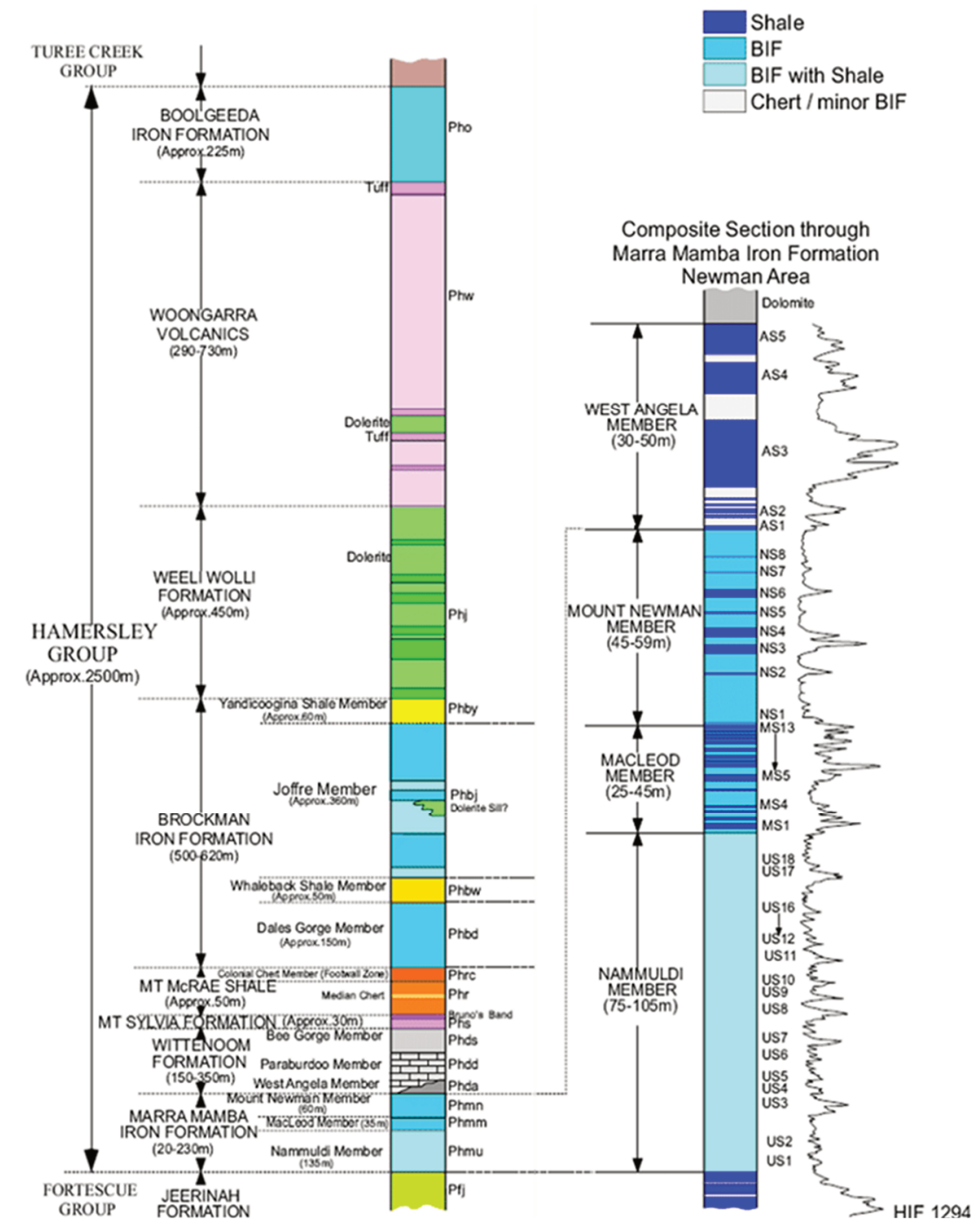

Figure 1 Stratigraphy of the Hamersley Group after RioTinto (2010) 


\section{Experimental methods}

PLT is an indirect compressive test which obtains the result by splitting the rock samples and then converts the tensile strength into compressive strength. A series of PLTs were carried out in the field and the results were calculated to estimate the anisotropy index $\left(I_{a}\right)$.

\subsection{Point load test}

Laboratory-based UCS testing is high cost and there is a strict requirement of sample length to diameter ratio making compliant samples difficult to obtain especially in weathered rock due to the broken nature of the rock mass. Indirect compressive tests such as point load strength $\left(I_{S(50)}\right)$ has been used to predict the UCS as discussed by Bieniawski (Bieniawski 1975), Broch et al. (Broch \& Franklin 1972) and D'Andrea et al. (1964) in the mining industry since decades ago. These tests are easier to carry out because they necessitate less or no sample preparation and the testing equipment is less complicated. By the loading direction, the PLT can be divided into diametral and axial PLT tests. The loading of a diametral test is parallel to the core crosssection and an axial is tested perpendicular to the core cross-section. For bedded BIF and BIF shale, the diametral PLT direction is normally parallel to the weak bedding plane and the result is much lower than the axial PLT. Therefore, the axial PLT should be adopted for estimating the BIF UCS. This recommendation is proven by comparing axial and diametral PLT results in Chapter 4.2.

Highly weathered rock is normally very broken and selected test samples rarely meet the length to diameter ratio requirement for UCS laboratory testing. The effect of highly weathered samples on rock strength anisotropy has been assessed by PLT because there are many highly weathered rock pieces that satisfy the sample size requirement for PLT, as shown in Figure 2. This is an advantage of PLT compared with UCS testing.

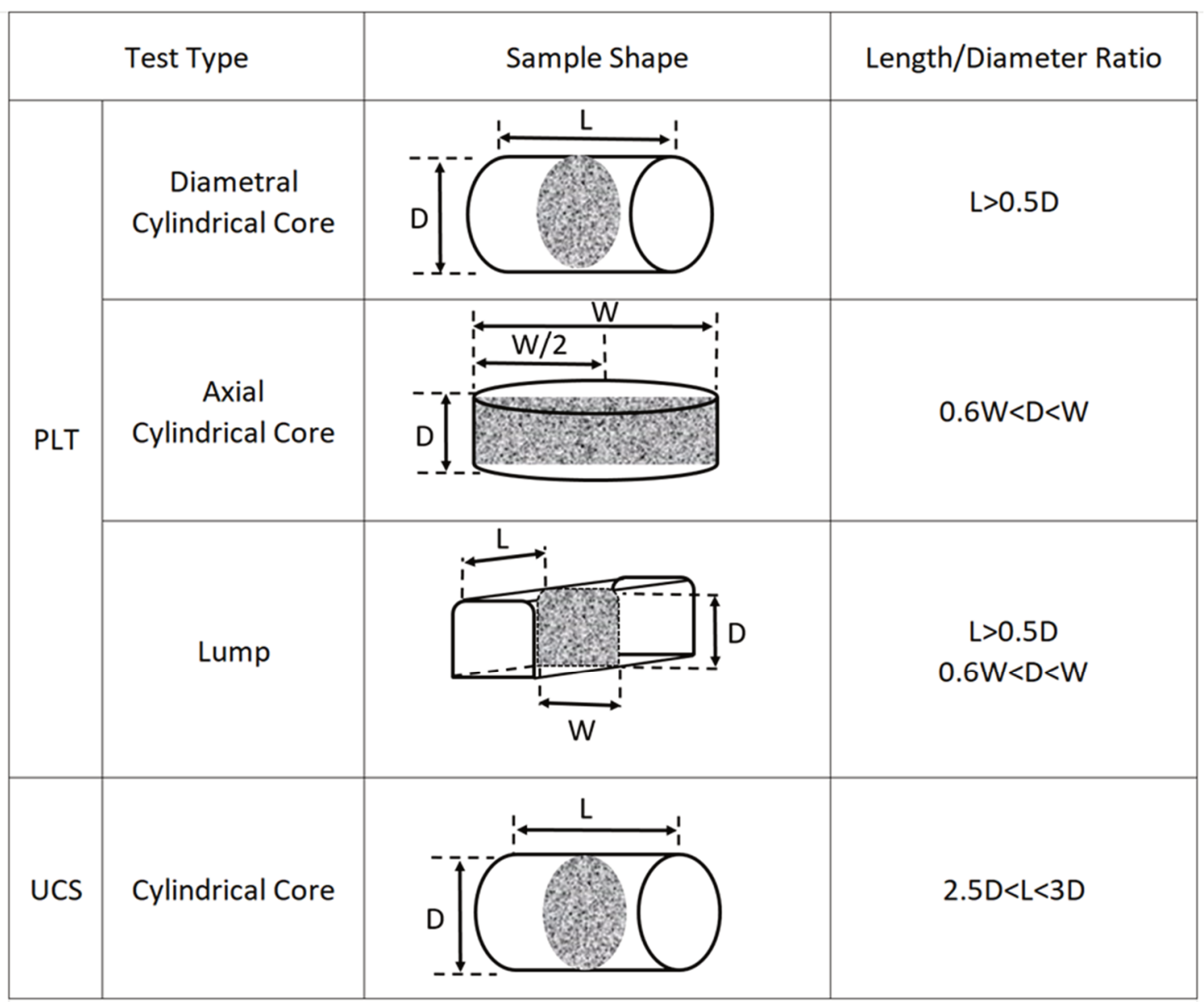

Figure 2 Point load test (PLT) and uniaxial compressive strength (UCS) samples size requirement (Standard Australia Limited 2007, 2013) 


\subsection{Sample selection and testing method}

A total of 48 samples including 28 units of highly weathered (HW) shale and 20 units of moderately weathered (MW) and slightly weathered (SW) BIF were tested using PLT during the 2015 RTIO Hope Downs 4 geotechnical drilling program as shown in Table 1.

Table 1 Point load test samples have been tested in 2015 Hope Downs 4 geotechnical drilling program

\begin{tabular}{lccc}
\hline Strat & Lithology & Weathering & Number of samples \\
\hline Dales Gorge & $\begin{array}{c}\text { Branded iron } \\
\text { formation (BIF) }\end{array}$ & $\begin{array}{c}\text { Moderately weathered } \\
\text { (MW) }\end{array}$ & 5 \\
Joffre (JOF) & BIF & MW & 8 \\
JOF & BIF & Slightly weathered (SW) & 7 \\
JOF & Shale & Highly weathered (HW) & 2 \\
Mount McRae & Shale & HW & 15 \\
Wittenoom & Shale & HW & 6 \\
Formation & & & 5 \\
Whaleback shale & Shale & HW & 5 \\
\hline
\end{tabular}

The PLT procedure follows the Method 4.1: Rock strength tests-Determination of point load strength index (AS 4133.4.1-2007) published by Standard Australia Limited (2007) and American Society for Testing and Material (ASTM) standard was also reviewed (ASTM International 2009). Diametral and axial tests were applied on the same piece of rock specimen to ensure the data is comparable. The test is implemented along bedding and axial test cuts across the bedding. The test was carried out by the following steps:

- The diametral test was conducted (Figure 3)Figure to split the sealed rock in the direction parallel to the bedding.

- The axial test was then applied in the split rock perpendicular to the bedding plane as shown in Figure 4.

- The peak load $(\mathrm{kN})$ applied when the sample is broken was recorded.

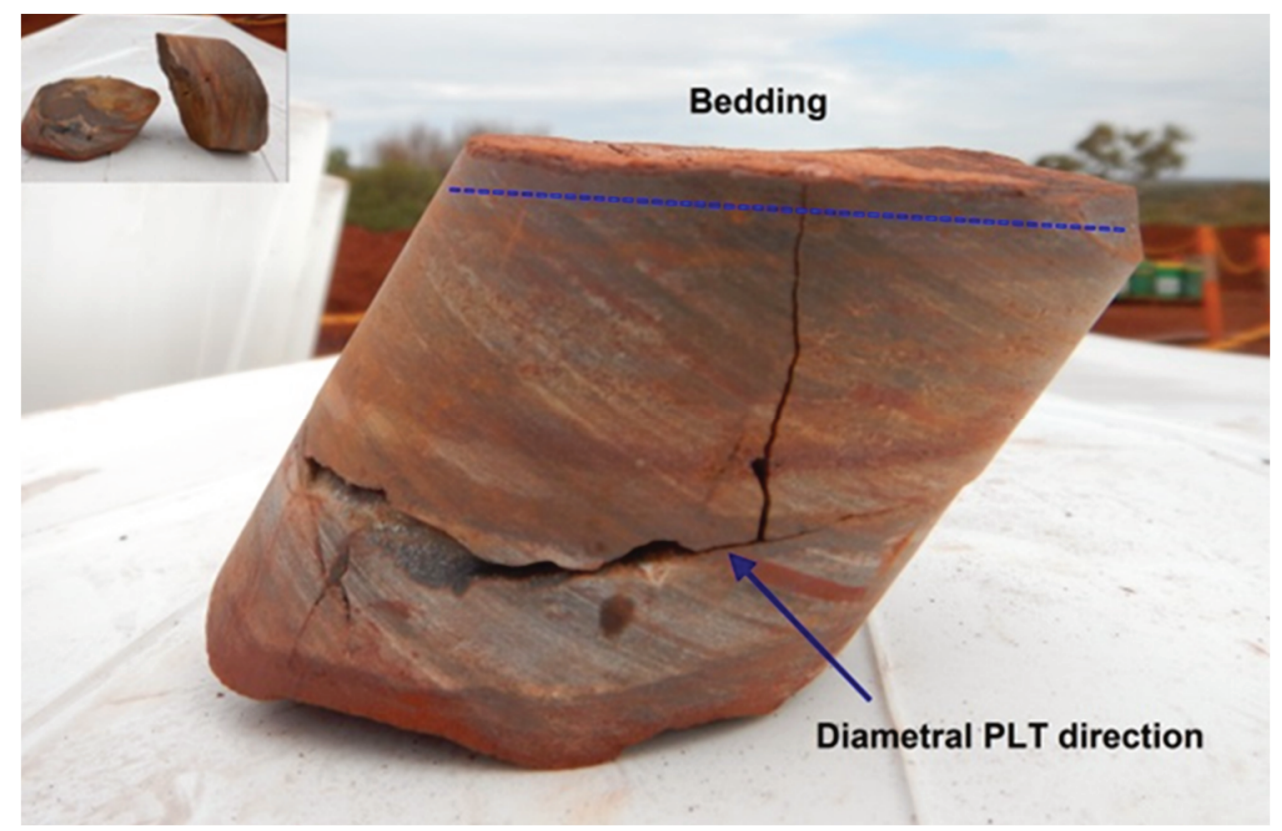

Figure 3 Loading direction and bedding orientation of diametral point load test (PLT) 


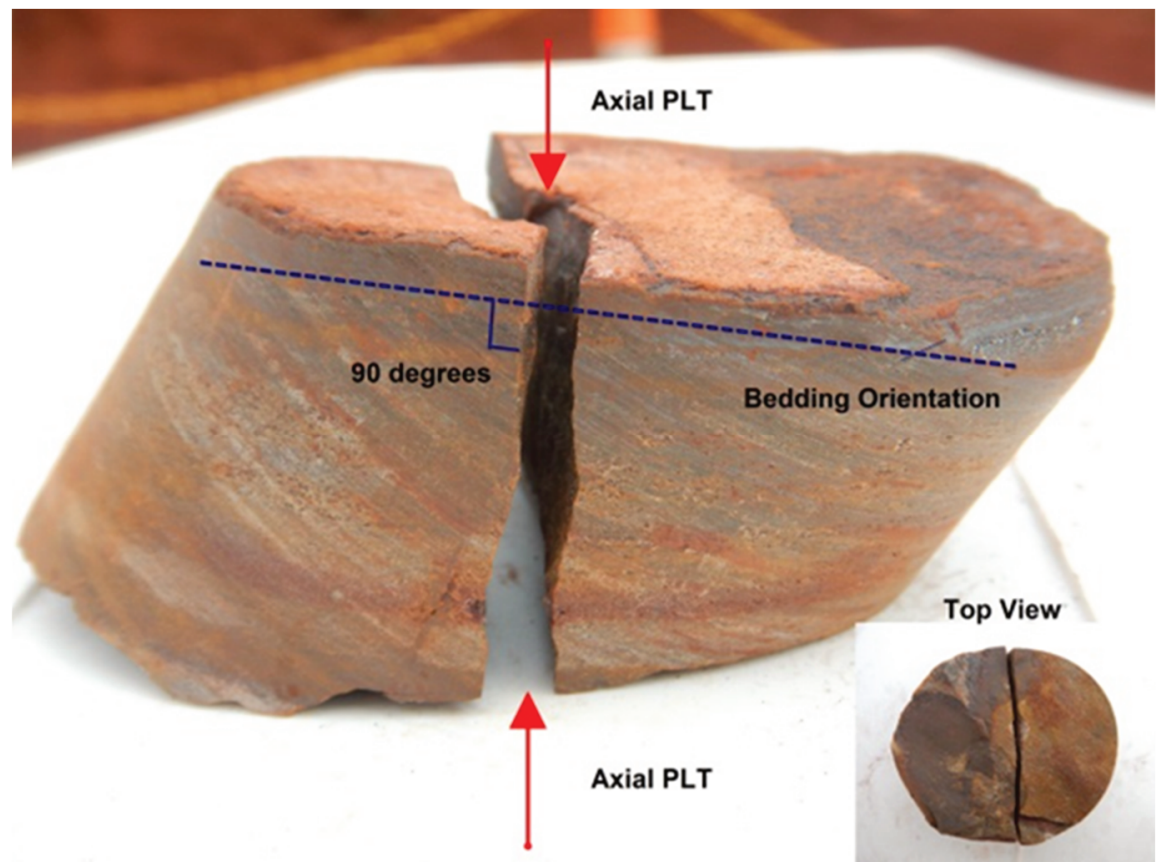

Figure 4 Loading direction and bedding orientation of axial point load test (PLT)

\section{$4 \quad$ Results}

Point load strength $\left(I_{s(50)}\right)$ in diametral and axial directions were calculated to estimate the anisotropic index $\left(I_{a}\right)$. It was concluded that axial and diametral $I_{s(50)}$ have a linear relationship and axial $\left.I_{s(50)}\right)$ is recommended for estimating UCS.

\subsection{PLT type effects}

The point load strength and point load strength index were calculated by the following equations from Method 4.1: Rock strength tests-Determination of point load strength index (AS 4133.4.1-2007) (Standard Australia Limited 2007) and the methods suggested by Galvan et al. (2014) for the different PLT test types.

\subsubsection{Diametral point load test}

The uncorrected point load strength $\left(I_{s}\right)$ is calculated by the following Equation 1 :

$$
I_{S}=\frac{P \times 1000}{D^{2}}
$$

where:

$$
\begin{aligned}
& I_{s}=\text { uncorrected point load strength (MPa). } \\
& P=\text { load at failure }(\mathrm{kN}) . \\
& D=\text { platen separation }(\mathrm{mm}) .
\end{aligned}
$$

The corrected point load strength $\left(\mathrm{I}_{\mathrm{s}(50)}\right)$ was then calculated from the following Equation 2:

$$
I_{S(50)}=I_{S} \times\left(\frac{D}{50}\right)^{0.45}
$$

where:

$$
\begin{aligned}
& I_{s(50)}=\text { point load strength normalised to a cylindrical specimen of } 50 \mathrm{~mm} \text { in diameter (MPa). } \\
& I_{s}=\text { uncorrected point load strength }(\mathrm{MPa}) . \\
& D=\text { platen separation }(\mathrm{mm})
\end{aligned}
$$




\subsubsection{Axial point load test}

The uncorrected point load strength $\left(I_{s}\right)$ is calculated by the following Equation 3:

$$
I_{S}=\frac{P \times 1000}{D_{e}{ }^{2}}
$$

where:

$\mathrm{I}_{\mathrm{s}}=$ uncorrected point load strength (MPa).

$P=$ load at failure $(\mathrm{kN})$.

$D_{e}=$ equivalent core diameter which can be calculated by Equation 4:

$$
D_{e}=\sqrt{\frac{4 A}{\pi}}
$$

$A=$ minimum cross-section area of the plane through the platen points $\left(\mathrm{mm}^{2}\right)$

Then the point load strength index $\left(\mathrm{I}_{\mathrm{s}(50)}\right)$ is calculated by Equation 5:

$$
I_{S(50)}=I_{S} \times\left(\frac{D_{e}}{50}\right)^{0.45}
$$

where:

$$
\begin{aligned}
& I_{s(50)}=\text { point load strength normalised to a cylindrical specimen of } 50 \mathrm{~mm} \text { in diameter (MPa). } \\
& I_{s}=\text { uncorrected point load strength }(\mathrm{MPa}) . \\
& D=\text { platen separation }(\mathrm{mm})
\end{aligned}
$$

\subsection{Point load strength index $\left(\mathrm{I}_{s(50)}\right)$ by point load test types and stratigraphy}

The point load strength index $\left(I_{s(50)}\right)$ for shale and BIF samples were calculated and analysed statistically and the results were discussed to estimate anisotropic index $\left(I_{a}\right)$.

\subsection{1 $\quad I_{s(50)}$ shale samples}

The axial PLT's $I_{s(50)}$ is generally higher than the diametral PLT $I_{s(50)}$ as shown in Figure 5 . The axial $I_{s(50)}$ median and mean are 2 to 2.5 times than diametral $I_{s(50)}$.

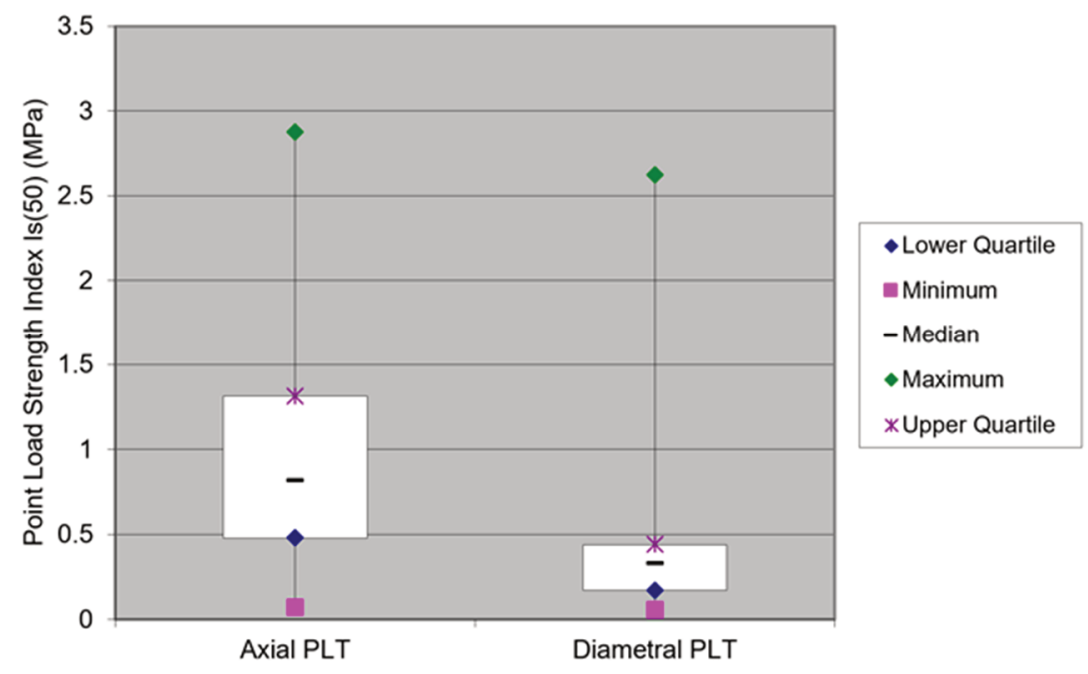

Axial PLT
\begin{tabular}{|l|l|}
\hline Lower Quartile & 0.48 \\
\hline Minimum & 0.07 \\
\hline Median & 0.82 \\
\hline Maximum & 2.88 \\
\hline Upper Quartile & 1.32 \\
\hline Mean & 1.04 \\
\hline \multicolumn{2}{|c|}{ Diametral PLT } \\
\hline Lower Quartile & 0.17 \\
\hline Minimum & 0.06 \\
\hline Median & 0.33 \\
\hline Maximum & 2.62 \\
\hline Upper Quartile & 0.44 \\
\hline Mean & 0.47 \\
\hline
\end{tabular}

Figure 5 Shale axial and diametral $\mathrm{I}_{\mathrm{s}(50)}$ Box-Whisker plot and statistical data 


\subsection{2 $\quad I_{s(50)}$ - Banded iron formation samples}

The anisotropy degree of MW and SW BIF is generally lower than HW shale samples from the Box-Whisker plots in Figures 6 and 7.

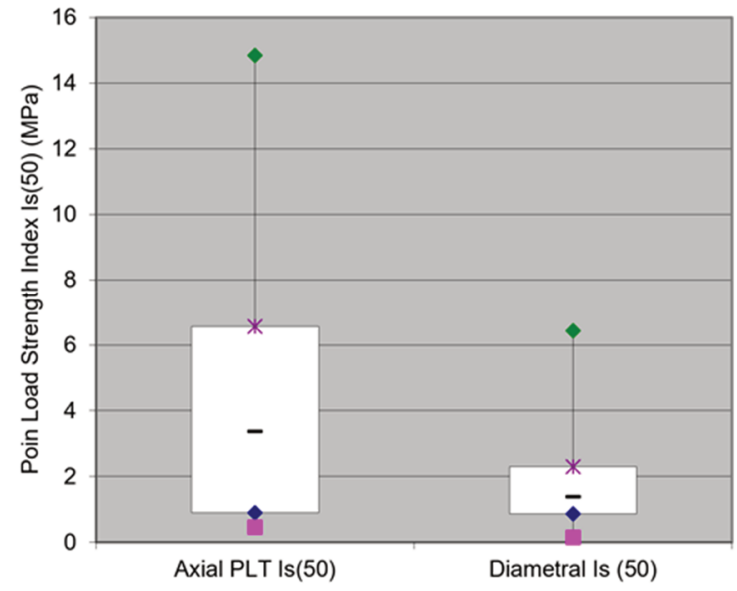

- Lower Quartile

Minimum

-Median

- Maximum

*Upper Quartile

\begin{tabular}{|l|}
\multicolumn{2}{|c|}{ Axial PLT Is(50) } \\
\begin{tabular}{|l|c|}
\hline Lower Quartile & 0.90 \\
\hline Minimum & 0.46 \\
\hline Median & 3.36 \\
\hline Maximum & 14.84 \\
\hline Upper Quartile & 6.56 \\
\hline Mean Diametral Is (50) \\
\hline \multicolumn{2}{|c|}{} \\
\hline Lower Quartile & 0.86 \\
\hline Minimum & 0.15 \\
\hline Median & 1.37 \\
\hline Maximum & 6.43 \\
\hline Upper Quartile & 2.30 \\
\hline Mean & 2.05 \\
\hline
\end{tabular}
\end{tabular}

Figure 6 Joffre member, moderately weathered banded iron formation (JM MW BIF) axial and diametral $\mathrm{I}_{(50)}$ Box-Whisker plot and statistical data

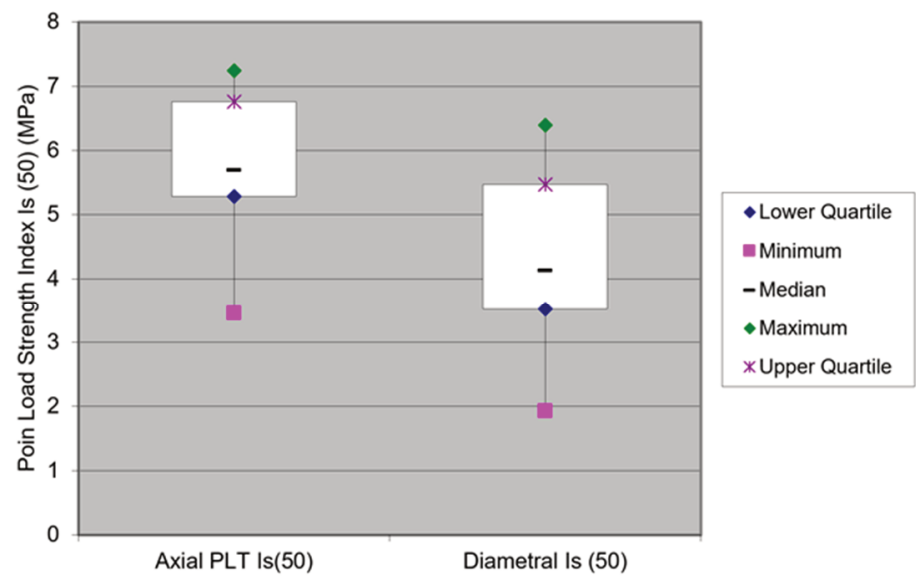

Axial PLT Is $(50)$
\begin{tabular}{|l|l|}
\hline Lower Quartile & 5.28 \\
\hline Minimum & 3.45 \\
\hline Median & 5.69 \\
\hline Maximum & 7.25 \\
\hline Upper Quartile & 6.76 \\
\hline Mean & 5.78 \\
\hline \multicolumn{2}{|c|}{ Diametral Is (50) } \\
\hline Lower Quartile & 3.52 \\
\hline Minimum & 1.93 \\
\hline Median & 4.13 \\
\hline Maximum & 6.39 \\
\hline Upper Quartile & 5.47 \\
\hline Mean & 4.35 \\
\hline
\end{tabular}

Figure 7 Joffre member, slightly weathered banded iron formation (JOF SW BIF) axial and diametral $\mathrm{I}_{\mathrm{s}(50)}$ Box-Whisker plot and statistical data

The mean and median of $I_{s(50)}$ are summarised in Table 2 and it can be concluded that:

- JOF MW BIF (Figure 6) - axial PLT $\mathrm{I}_{\mathrm{s}(50)}$ has median (3.36 MPa) and mean (4.74 MPa) 2-2.5 times higher than diametral PLT $\mathrm{I}_{\mathrm{s}(50)}$ 's median(1.37 MPa) and mean (2.05 MPa).

- JOF slightly weathered (SW) BIF (Figure 7) - axial PLT $\mathrm{I}_{s(50)}$ has slightly higher (less than 1.5 times) median $(5.69 \mathrm{MPa})$ and mean $(5.78 \mathrm{MPa})$ than diametral PLT $\mathrm{I}_{\mathrm{s}(50)}$ 's median $(4.13 \mathrm{MPa})$ and mean (4.35 MPa).

Therefore, it can be concluded that:

- Weathered shale and moderate weathered BIF have a higher degree of anisotropic index than slightly weathered BIF.

- The axial PLT strength is $\sim 2$ to 2.5 times higher than diametral PLT strength for weathered shale and moderate weathered JOF BIF.

- The axial PLT strength is $\sim 1$ to 1.5 times higher than diametral PLT strength for slightly weathered JOF BIF. 
Table 2 Point load test samples' point load strength index $I_{s(50)}$ and anisotropic index $I_{a}$

\begin{tabular}{|c|c|c|c|c|c|c|}
\hline \multirow[t]{2}{*}{ Strength index } & \multicolumn{2}{|c|}{$\begin{array}{l}\text { Joffre (JOF) highly } \\
\text { weathered shale }\end{array}$} & \multicolumn{2}{|c|}{$\begin{array}{l}\text { JOF moderately weathered } \\
\text { branded iron formation (BIF) }\end{array}$} & \multicolumn{2}{|c|}{ JOF slightly weathered BIF } \\
\hline & Median & Mean & Median & Mean & Median & Mean \\
\hline Axial $I_{s(50)}(\mathrm{MPa})$ & 0.8 & 1.0 & 3.4 & 4.5 & 5.7 & 5.8 \\
\hline $\begin{array}{l}\text { Diametral } \mathrm{I}_{\mathrm{s}(50)} \\
(\mathrm{MPa})\end{array}$ & 0.3 & 0.5 & 1.4 & 2.1 & 4.1 & 4.4 \\
\hline Anisotropic index $\mathrm{l}_{\mathrm{a}}$ & 2.5 & 2.2 & 2.5 & 2.2 & 1.4 & 1.3 \\
\hline
\end{tabular}

\subsubsection{Relationship between axial and diametral $I_{s(50)}$}

The corrected diametral and axial point load index $I_{s(50)}$ of shale and BIF were plotted in Figures 8 and 9 below. The BIF samples were grouped by slightly weathered and moderate weathered.

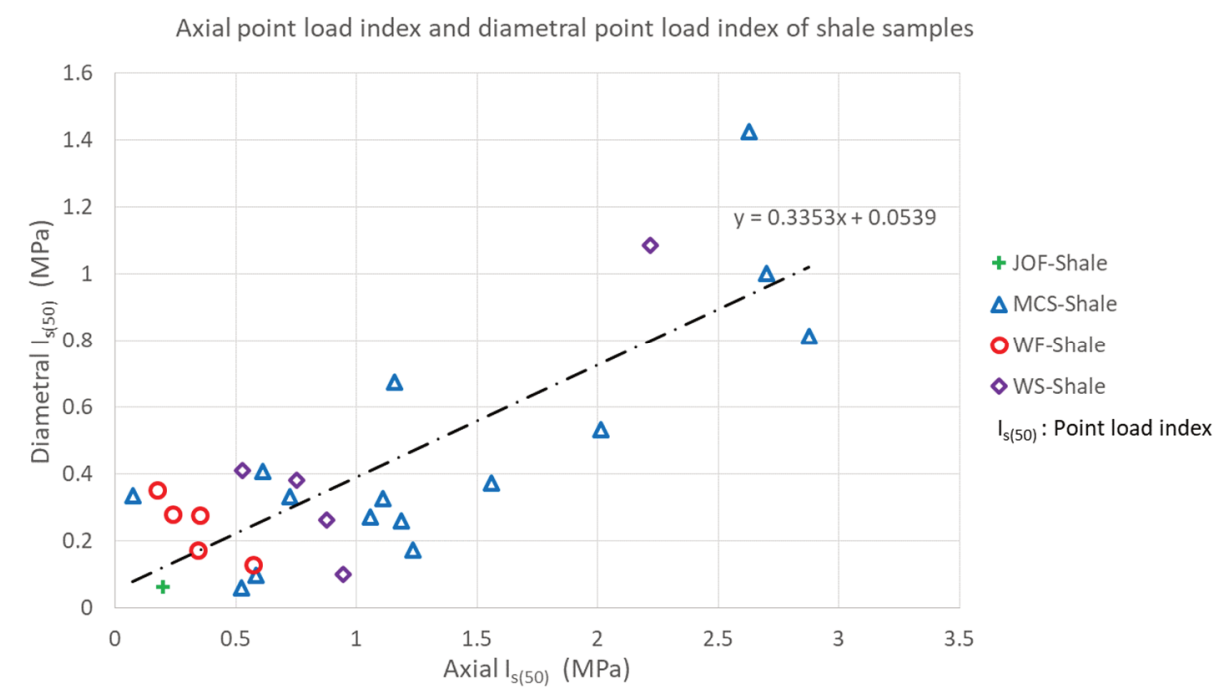

Figure 8 Shale axial point load index versus diametral point load index by stratigraphy and lithology

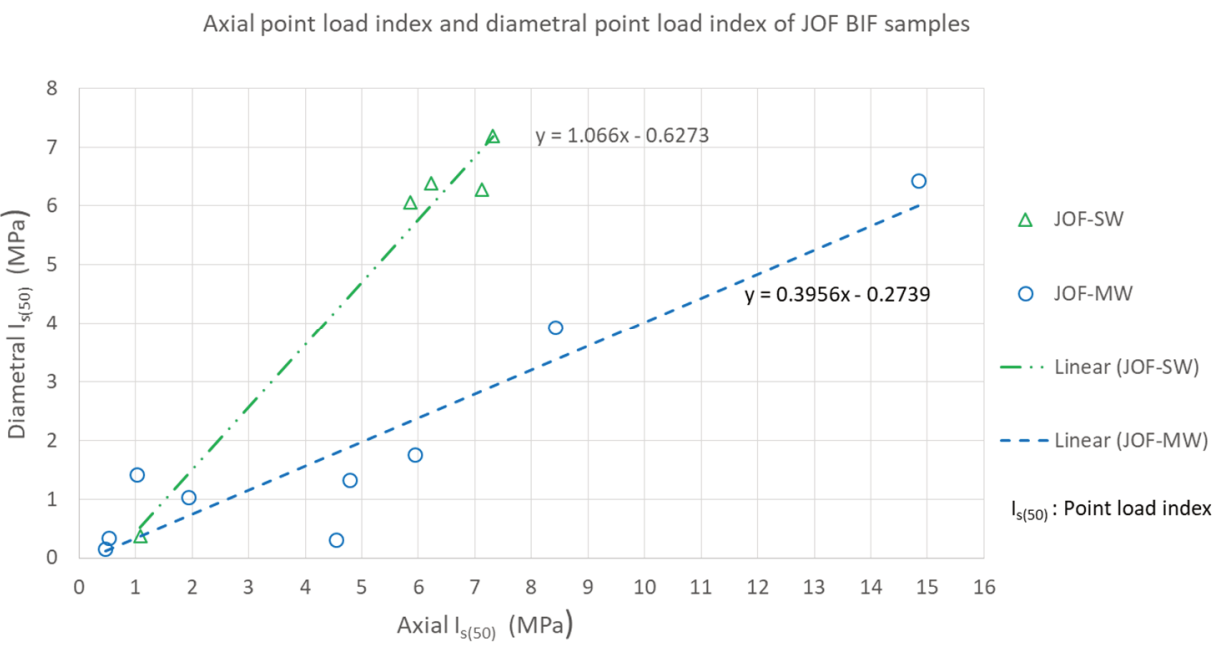

Figure 9 Banded iron formation axial point load index versus diametral point load index by stratigraphy and weathering 
The anisotropy index $I_{a}$ was calculated as the ratio between the corrected axial point load strength index and the diametral point load strength index. It can also be used to make the diametral PLT results more conformed to intact rock strength by converting to axial PLT because of the following observations:

- For HW bedded shale, the point load strength index in the direction perpendicular to bedding is three times of the strength parallel to the bedding $: I_{\alpha(U C S)}=3$ as shown in Equation 6 .

$$
\text { Anisotropy Index }\left(I_{a}\right)=\frac{{\text { Axial } I_{S(50)}}_{\text {Diametral } I_{S(50)}}}{\text { Diatra }}=3
$$

where:

$I_{s(50)}=$ point load strength normalised to a cylindrical specimen of $50 \mathrm{~mm}$ in diameter (MPa).

- For MW BIF, the point load strength index $I_{\alpha(U C S)}=1.25$ as shown in Equation 7.

$$
\text { Anisotropy Index }\left(I_{a}\right)=\frac{\text { Axial }_{S(50)}}{\text { Diametral }_{s(50)}}=1.25
$$

where:

$I_{s(50)}=$ point load strength normalised to a cylindrical specimen of $50 \mathrm{~mm}$ in diameter (MPa).

- For slightly weathered and fresh BIF, the point load strength index $I_{\alpha(U C S)}=1$ as shown in Equation 8.

$$
\text { Anisotropy Index }\left(I_{a}\right)=\frac{\text { Axial }_{S(50)}}{\text { Diametral } I_{S(50)}}=1
$$

where:

$I_{s(50)}=$ point load strength normalised to a cylindrical specimen of $50 \mathrm{~mm}$ in diameter (MPa).

It is observed that the anisotropy index is proportional to the weathering degree because the slightly weathered rock has more sealed bedding and the degree of alteration is normally higher.

It also can be concluded that only axial PLT should be used to estimate the BIF UCS because diametral PLT gives lower tensile strength due to the weak bedding parallel load direction. Diametral PLT results only can be used after converting to axial PLT results by using the factors from Equations 6, 7 and 8 .

\section{Conclusion}

In geotechnical slope design, the rock mass anisotropy has a greater impact on slope stability than intact rock fabric. This is especially the case when the weak shale bands are at unfavourable orientations to the pit wall, as slope instability in the Pilbara BIF deposits is mainly controlled by shale band shear strength. Fabric BIF strength anisotropy is the main control factor when the bedding dips into the pit wall and potential failure paths must cut break through the rock mass. Therefore, $\sigma_{\mathrm{ci}}$ needs to be selected with caution as it can impact the slope angle and stripping ratio significantly.

As one of the major input parameters into the Hoek-Brown failure criterion, UCS $\sigma_{\mathrm{ci}}$ can be estimated by laboratory compressive tests (e.g. UCS and triaxial test) and PLT.

The number of valid UCS results is normally limited because: (1) the UCS test is expensive, (2) an invalid extremely low UCS can be reported due to pre-existing defects/cracks inside the samples, and (3) operational faults (e.g. fast loading speed) can occur during the testing which make the results invalid.

After filtering the invalid UCS tests, there are normally very limited numbers of results that can be used for design strength selection, which makes the strength model unrepresentative.

It is recommended to use a large number of axial PLTs during data collection because it best represents the UCS test in anisotropic bedded material. The diametral PLT strength needs to be converted to axial PLT strength before use. 
The main limitations of this paper are:

- The limited samples for analysis without wide coverage of stratigraphic units. It has been demonstrated from historical geotechnical studies in the Pilbara that BIF from different stratigraphic units has variable strengths. The unfiltered dataset could result in potentially inaccurate results. Equations 6,7 and 8 should only be used as a pilot empirical method to estimate $\sigma_{\mathrm{ci}}$ in Pilbara BIF.

- The anisotropic behaviour was only estimated in the direction parallel and perpendicular to bedding but not the varying angle between bedding and load. The sedimentary rock anisotropy regarding the bedding dips will be discussed in the following work by reviewing laboratory compressive tests including UCS and triaxial tests.

\section{Acknowledgement}

I would like to thank Dr William Darlington, Timothy Johnson, Dr Chris Ware, Solomon Oppong and Mitchell Weekes who provided technical review for this research.

\section{References}

ASTM International 2009, Standard Test Method for Determination of the Point Load Index of Rock (ASTM D5731-05), ASTM International, West Conshohocken.

Bieniawski, ZT 1975, 'Point load test in geotechnical practice', Engineering Geology, vol. 9, no.1, pp. 1-11.

Broch, E \& Franklin, JA 1972, 'Point load strength test', International Journal of Rock Mechanics and Mining Sciences, vol. 9, no. 6, pp. 669-697.

D'Andrea, D.V, Fisher, RL \& Fogelson, DE 1964, 'Prediction of compression strength from other rock properties', Colorado School of Mines Quarterly, vol. 59, no. 4B, pp. 623-640.

Galvan, M, Preciado, J \& Seron, J 2014, Correlation between the point Load Index Is(50), and the Resistance to Unconfined Compression in Limestone from The Comunidad Valenciana, Spain, ACTA Geotechnica Slovenica, University of Maribor, Maribor, viewed 15 December 2019, http://www.fg.uni-mb.si/journal-ags/pdfs/AGS_2014-2_article_3.pdf

Mercer, K 2012, The history and development of the anisotropic linear model: part 1, July 2012 newsletter, Australian Centre of Geomechanics, Perth, viewed 22 September 2019, https://www.rocscience.com/documents/pdfs/uploads/8647.pdf

Rio Tinto 2010, Geology and mineralogy of the Hamersley Province ores, unpublished.

Standards Australia Limited 2007, Method 4.1: Rock strength tests-Determination of point load strength index (AS 4133.4.1-2007), Standards Australia Limited, Sydney.

Standards Australia Limited 2013, Method 4.3.2: Rock strength tests-Determination of the deformability of rock material in uniaxial compression-Rock strength less than 50 MPa (AS 4133.4.3.2-2013), Standards Australia Limited, Sydney. 